\title{
Organization Goal-Oriented Requirements Elicitation Process to Enhance Information System
}

\author{
Fransiskus Adikara $^{1}$, Bayu Hendradjaya ${ }^{2}$, Benhard Sitohang ${ }^{3}$ \\ ${ }^{1}$ Department of Information Technology, Esa Unggul University, Indonesia \\ ${ }^{2,3}$ School of Electrical Engineering and Informatics, Institute Technology of Bandung, Indonesia
}

\begin{tabular}{l}
\hline \hline Article Info \\
\hline Article history: \\
Received Sep 28, 2016 \\
Revised Oct 22, 2016 \\
Accepted Nov 2, 2016 \\
\hline
\end{tabular}

Keyword:

Goal-oriented requirements engineering

Information system

Requirements engineering

Software engineering

\begin{abstract}
This paper introduces and proposes an approach in goal-oriented requirements elicitation process that using Key Performance Indicators (KPIs), in information system enhancement process. KPIs can be used to control and reduce user requirements problems caused by personal interests of users in requirements elicitation process. An information system enhancement project for a distribution company has been used as a case study to demonstrate this approach. The case study shows that the requirements can be elicited from the organization goals and current information system condition rather than from user requirements. This approach also showed that KPIs have been able to control some user requirements that have difference point of view with high level stakeholder requirements. Compared with the previous research, IT goals and KPIs are more easily identified in the enhancement process rather than through development of a brand new information system.
\end{abstract}

Copyright () 2016 Institute of Advanced Engineering and Science. All rights reserved.

\section{Corresponding Author:}

Fransiskus Adikara,

School of Electrical Engineering and Informatics,

Institute Technology of Bandung,

Jalan Ganesha, Bandung, Indonesia.

Email: adikara@students.itb.ac.id

\section{INTRODUCTION}

Information System gives added values that can significantly increase the competitive advantage of the business[1-2]. However, the information system still faces several problems, especially if the information system cannot support the current business process improvements and complexities. The most common problems in enhancing the current information system occur in requirements engineering phase. This happens because requirements are constantly changing in line with the improvement of an organizational business process. Improper and incomplete requirements can greatly affect to the quality and success rate of information systems development [3].

Research [4] has shown that in information system projects, only $41.9 \%$ are able to fulfill operational requirements and only $16.1 \%$ are able to fulfill managerial requirements. Based on this data, the requirements phase process need to be improve so that the results can better fulfill managerial requirements, rather than just fulfilling operational requirements. As in new information system development process, the risk may increase when user requirements appear to be against the standard or the best practices that are usually followed [5] in information system enhancement process. Understanding the users' needs is essential, however it may be better to apply a general and best practices first before dealing with the user requirements.

GORE approach is expected to minimize the emergence of requirements originated from user interests [6]. In a previous paper [7], an extension of GORE approach, that uses and mainly focus on the organization goals (the overall objectives, purpose, and general mission of an organization) and IT goals (the expected result of IT implementation and its role in supporting the achievement of organization goals) have 
been proposed to elicit system requirements, so the system functions and the resulting requirements can be more qualified and relevant to the organization's objectives rather than other objectives (including user). In previous paper, the case study used an information system project in an organization that never use any information system. In this paper, the organization already have information system that still running in their current business operation. The new improvement of requirements elicitation approach proposes in this paper to enhance the information system in an organization, to fulfill their new business process complexity. This research want to identify the difference of the requirements result and the requirements process in comparison to the previous research [7]. The case study also demonstrates how KPIs can be used in this requirements elicitation approach to reduce user requirements caused by user interests and unproper user operational routines. The purpose of KPIs in this approach are to make sure that each defined goals can be achieved only if the enhancement in information system can be run properly based on requirements elicitation that came from organization and IT goals, instead of user requirements or user operational routines.

An information system enhancement project in a distribution company was used as a case study to demonstrate this approach. The company have already been using their current information system for 10 years. The current information system is used to manage and organize only 5 distribution branches and around 500 variations of items at first. Today, the company has grown to 16 branches and around 1,500 item variations to be managed. There are also new operation procedures and new business processes to apply these days resulting in a more complex business processes. The current information system needs to be enhanced and new modules need to be developed to fulfill the new business process procedures when the need arises. Result from this case study demonstrate how the proposed approach can be use in the information system enhancement process and show that the KPIs can be more easily identified.

In Section 2 of this paper, we start with an explanation about our proposed approach for requirements elicitation process, and in Section 3, we explain about research method. In Section 4 we provide an overview of our case study and discuss the implementation result in this Section, and finally we conclude it in Section 5.

\section{ORGANIZATION GOAL-ORIENTED REQUIREMENTS ENGINEERING PROCESS}

Requirements elicitation is the first activity in requirements engineering process that collects and discovers the purpose of a new information system. We introduce an approach which uses organization goals that are extracted into IT goals with KPIs in each goal. We have also introduced our definition of GORE terminologies in a previous paper [7].

The new improvement approach that proposes in this paper is described in Figure 1. The first step is to define the existing profile of the organization. Engineers with high level stakeholders [8] (owner or Board of Directors) will discuss and extract IT Goals that are expected to be achieved by the information system enhancement. Furthermore, we define the KPIs of each goal as target to be achieved. These KPIs are also used as control tools. When we define the KPIs for each goal, engineers and stakeholders must make sure that the KPIs can only be achieved if the stakeholder and users use the new enhanced information system according to its goals. This factor will reduce user requirements problems caused by user intersts, unproper user operational routines or user point of view that different with stakeholders, because the defined goals come from the organization, not from users. If the elicitation process just use general goals without KPIs for requirements elicitation, users can still define some goals, tasks, or resources which come from their point of view, knowledge or their routine operational behavior [9].

This approach use Goal-oriented Requirements Language (GRL) [10] as the goal-modeling language to describe the relationships between each elements. The result of this elicitation process is the organization goals and IT goals that have KPIs, to identify and define system requirements (functional requirements). In next sub-Section, detailed propose approach activity will be explain based on Figure 1.

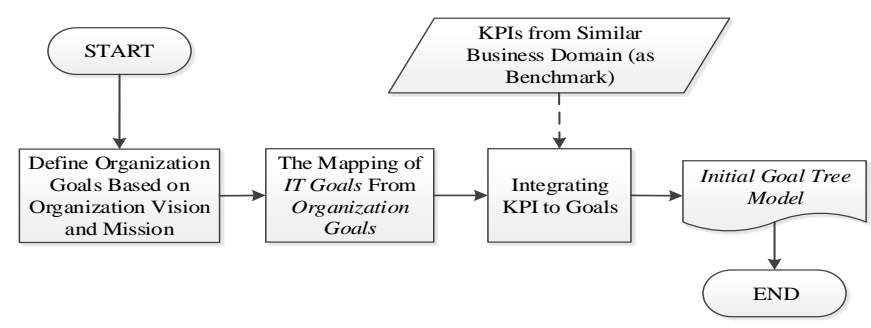

Figure 1. Organization Goal-Oriented Requirements Elicitation Flowchart Diagram 


\subsection{Define Organization Goals Based on Organization Vision and Mission}

Organization goals are the overall objective, purpose and general mission of an organization. Organization goals are defined and established by the high level stakeholders. To be achieved, the goals must be socialized and communicated within all elements of the organization. Organization goals will become company's philosophy; providing guidance for employees in order to meet the stakeholders' expectation [11].

Nowadays, the role of information and communication technology becomes an important part in the organization to achieve the organization goals. The results of the information technology application has taken an important role in the achievement of organization goals, on the other hand, business and/or organization goals are important things to be used in the information systems [8]. The expected result of information technology application in a company and its role in supporting the achievement of organization goals can be interpreted as an Information Technology Goals (IT Goals) [12]. In this case study, IT Goals can also mean the function goal of new enhancement in information system.

The activities to define organization goals based on organization vision and mission undertaken by high level stakeholders and development teams in a group discussion are as follows:

1. Defining the vision and mission of the organization by the high level stakeholder.

2. Define the objectives of the organization (organization goal) by the stakeholders.

3. Setting priorities among the organization goals that will be mapped to IT Goals.

The results of this activity are the organization goals that will be used as the primary basis of information systems development.

\subsection{The Mapping of IT Goals from Organization Goals}

Table 1 will show how each IT Goals can support organization goals [12], so we know which IT goals must be achieved to make sure which organization goal will be achieved. With this mapping, we can also prioritize which IT goals we want to achieve with limited time and resources, and also in terms of new information system development goals.

Table 1. Mapping Organization Goals to IT Goals [7]

\begin{tabular}{lccc}
\hline & \multicolumn{3}{c}{ Organization Goals } \\
\hline IT Goals & $A$ & $B$ & $C$ \\
X & $\sqrt{ }$ & $\sqrt{ }$ & \\
Y & $\sqrt{ }$ & & $\sqrt{ }$ \\
Z & & $\sqrt{ }$ & $\sqrt{ }$ \\
\hline
\end{tabular}

The requirements elicitation approach propose to extract the initial purpose of organization goals onto each related IT goals in order to achieve it. Afterwards, the goals also extract and connect the goals to their related task and resources to achieve it. The approach also introduced an improved definition which was modified from GSTH [13] and GRL [14] definition in GORE terminology. The terminology definitions we use in this method is the same as those in the previous research [7]. With those terminologies, the requirements engineers define and describe the notation and relationship between goals using Goal Requirements Language (GRL) [10]. GRL method result the Goal Tree Model (GTM) that will show relationship between each element shown in Figure 2.

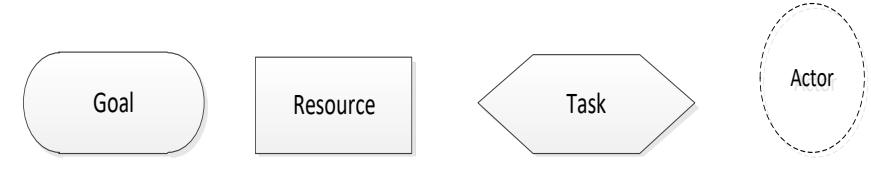

Figure 2. Goal Tree Model Elements [10]

\subsection{Integrating KPIs to Goals}

The KPIs in this proposed approach are able to show the progress and the level of achievement of goals. KPIs used in this approach are direct indicators. The direct indicators provide immediate value to a condition [15]. For example: the percentage of the right stock quantity in one month, the number of purchase orders that can be processed in one day, and so on. We have used KPIs to measure and improve the software process. KPIs have controlled each goal, that were used a system requirement that could better accommodate 
the needs of the organization or IT goals. Based on this, we integrate KPIs in requirements elicitation process to reduce user requirements based on users' own demands or user manual operational routines.

The activities to to identify the KPIs are as follows:

1. The stakeholders make a list of measures that are used in evaluating the achievement of each goal. If the organization has had an information system which is still running in the organization, as KPIs to be achieve, stakeholders can add the list of measures that the current system cannot achieve.

2. Stakeholder and developer team prioritize the measures and make sure that the measure can be a control tool for the goal we want to achieve. The measurement can only be achieved if stakeholders and users use the new enhanced information system according to its goals.

3. If these terms have been completed, the measures become KPIs.

4. KPIs can also come from organizations which share similar business domains [16]. These external KPIs can then be used to compare or benchmark our organization's KPIs.

5. KPIs then integrated with related goals.

Once everything is completed, the elicitation process produces Initial Goal Tree Model to illustrate the information systems requirements based on the organization expectation.

\section{RESEARCH METHOD}

The following are explanations of the research methods:

1. The research method used in this research is a case study;

2. The new improvement of organization goal-oriented requirements elicitation proposes in this research;

3. A case study conducted on an information system project for an organization that already has the information system and want to enhance the information system;

4. The purpose of the case study is to identify implementation differences in the requirements elicitation process between organization which have existing information systems with organization that do not have any information system;

5. This case study discuss the implementation and differences of elicitation process that occurs when organization goal-oriented requirements elicitation implemented;

6. High level stakeholders who participated in this case study are represented by commissioners of the company and operation director, and from the developers represented by Business Analyst and Systems Analyst.

7. Implementation of case study was conducted over 10 days in March 2015.

\section{RESULTS AND ANALYSIS}

This Section explain about overview of case study subject, continue with describe about implementation of organization goal-oriented elicitation process in case study. Finally a discussion about implementation result and differences analysis will end this Section.

\subsection{Overview of Case Study Subject}

The distribution company information system project has been used as a case study to demonstrate the elicitation approach in enhancing the information system. The existing information system could handle all the basic business processes from purchasing, inventory, and selling modules. The company was growing and the business processes were becoming more complex. The existing information system only covered the basic processes, so the user still needed more time and manual procedures to generate the proper reports they need. The system was also unable to integrate with their main principal company information system. The users also complained about the long data processing time, but because they had used this information system for a long time, they were already comfortable with some functions and procedures. The new elicition approach have been use to elicit system enhancement requirements for this company.

The main business of distribution company is to distribute their principal factory items to their distribution branches. The company also has some canvasing sales to direct sales of their goods to their retail channels. In the beginning, the information system only handled 5 distribution branches and managed around 500 items variation. Nowadays, they have 16 distribution branches and almost 1,500 items variation. This company's vision is to become the most professional and a nation-wide consumer goods distribution company in Indonesia. Meanwhile, this company's mission is to distribute consumer goods to all areas in Indonesia with professional, reliable, and trustworthy services. From the company's vision and mission, the company describes the organization's purpose as follows:

1. To increase sales and to widen distribution area to all provinces of Indonesia. 
2. To make goods turnover in the warehouse effective and to make sure that all goods are in the best quantity to distribute.

3. To improve purchasing and return goods control between internal distribution channels and to principals manufacturers.

4. To improve cost control and operational process efficiency.

At this point, the company had been using the information system that was bought 10 years ago to handle and manage their business process. The information system had handled end-to-end operations from purchasing, accounts payable, inventory, sales, account receivable, finance and accounting modules. These modules were integrated in a custom made Enterprise Resource Planning Information System (ERP-IS).

As explained above, the business has grown, the distribution channels and items variation had increased significantly in past 10 years. Some business processes has become more complex and the users must modify their reports produced by the current system. The operation director (OD) wanted to get more accurate information and faster reports production to improve their business. The OD needed to take faster and more accurate decisions in sales and marketing supported by the reports and information which come from the information systems. Therefore, the company wanted to create a new information system to manage their growing business processes and to make sure that their company objectives are achieved with this information system enhancement.

\subsection{The Implementation of Organization Goal-Oriented Requirements Elicitation Process}

Using organization goal-oriented requirements elicitation elicitation process, the process started with a small discussion group, attended by the commissioners of the company, operation director (from now they called as the stakeholder), the business consultant developer and system analyst developer (from now they called as the developer). The stakeholder and developer discussed the vision, missions, and objectives of the company and also their new expectations in information systems. Because the company has had an existing operating information system, the stakeholder and developer then discussed all the experiences and problems that arise from current information system and their expected solution in enhanced version of the current information system.

From this discussion, the developer have outlined company profile, current information system profile, and priority goals to achieve using the new system. One of the expected company/organization goal to be achieved is the improvement of purchasing and purchasing return control between internal distribution channels and to principals manufactures. The company wants to have a more accurate cost of goods sold (COGS) valuation of the distributed consumer goods as IT Goal.

In next meeting with the stakeholders, the developer have defined goals, tasks, resources and actors based on company existing business objectives (organization goals) and the current information system function (IT goals). The developer questioned the "how" and "why" to extract more goals and other elements (the same approach as Kaos [17], $\mathrm{i}^{*}$ [18] and GRL [14]). The company already had an information system, thus the developers asked and discussed with stakeholder about the existing information system daily operation procedure, as well as every unfinished and unaccomplished goals. Then, developers designed and identified subordinate goals, tasks, resources, and actors based on information above.

As the result from earlier phase of elicitation approach, the developer have developed a GTM. After that, KPIs are then determined for each goal. Again, the developer and stakeholder meet in a small group discussion to identify and define KPIs based on GTM from an earlier phase. To define the KPIs, the small group discussions gathered and defined the priority of measurements which determine the achievement of the goals. Each KPI must indicate the achievement of the goals and must be measurable.

In the initial phase, the OD wanted the enhanced system to handle all complex operation processes that the current system cannot handle. The OD and IT manager could define the KPIs based on their experience with current system and the expected achievement from the enhanced functions of the new system.

The problems occur when stakeholders define the operation resources and tasks to achieve those KPIs. The stakeholder and developer already define "COGS calculation must use price from invoice" as KPI for "Control Purchase Return" goal. In process to define operation resources and tasks, OD still obtain inputs from their operative users, specially about Cost of the Good Sold (COGS) calculation and tax calculation procedures. When the developer crosschecked with the best practices procedures, some current procedures were not appropriate and there were miscalculation of COGS and tax rounding.

With the current information system, price and COGS calculation could be edited if the purchased goods have to be returned to the principal. The price could change and was not set with reference to the previous invoice that came from the supplier. Contrary to the OD's point of view, this price adjustment could not be executed without someone's approval and must refer to the invoice that came from supplier. Based on 
KPI to be achieved by the goal, the OD wanted this user routine procedure change and enhanced based on the best practices procedures that proposed by the developer.

The above example demonstrates that the elicitaion process have potentials to raise the risk of the user requirements. With the right KPIs and maximum control to achieve KPIs, this risk can be reduced. KPIs set for each defined goals can only be achieved if the new information system can be run properly. After that, KPIs control the goals, that become system requirements that should accommodate the needs of organization or IT goals better rather than interest of users. After the KPIs were set, KPIs and relevant goals were mapped using the GRL. We have shown the requirements elicitations in GRL model (Figure 3).

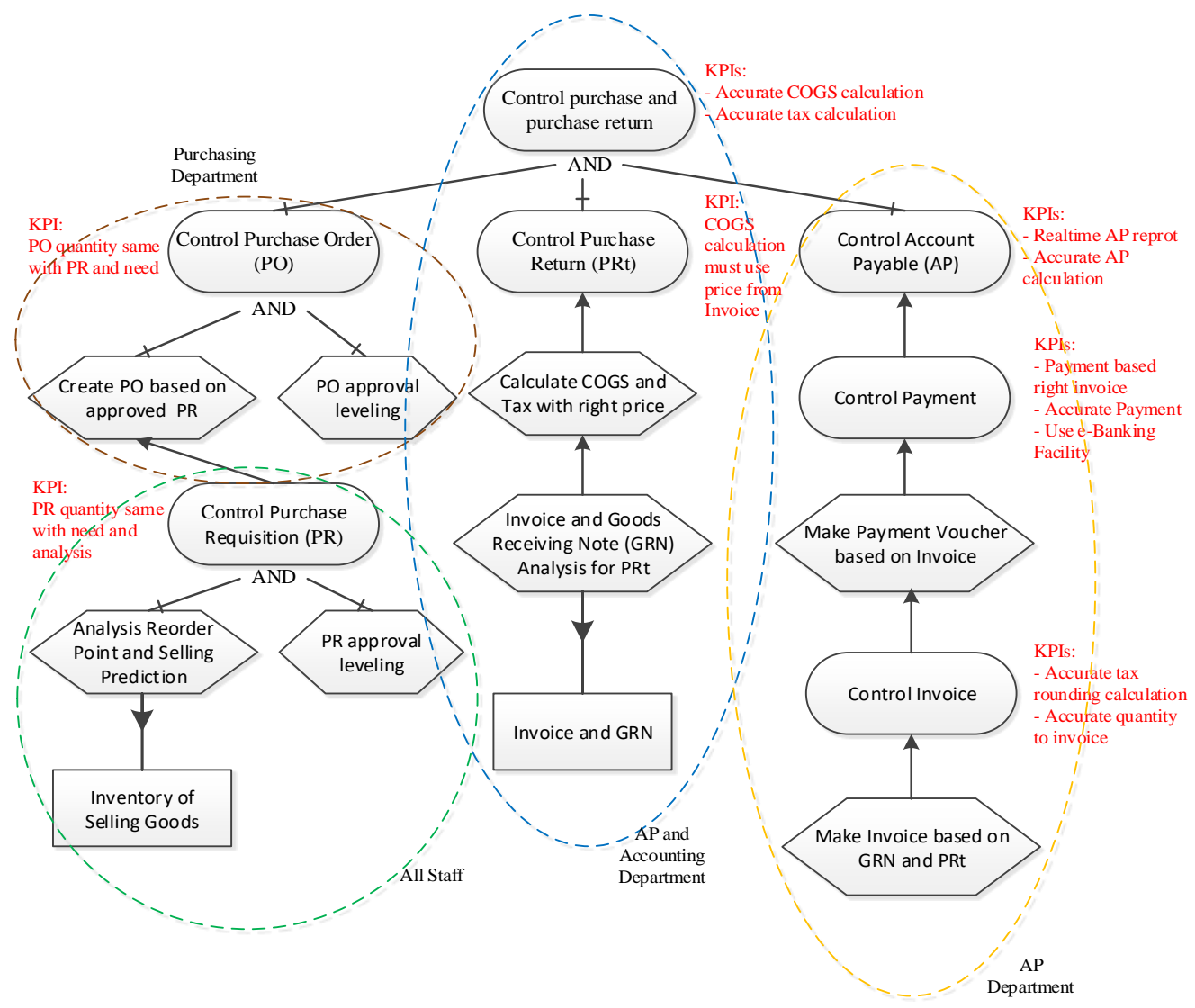

Figure 3. Initial Goal Tree Model from Elicitation Phase

\subsection{Result of Implementation and Discussions}

In previous research [7], a similar method of the elicitation process have been proposed to be implemented in a transportation company, that had no information system. In this research, the elicitation process have been improved from previous method and applied to distribution company that already has an information system. Next paragraph will be discussing the differences of the implementation result between case study in previous research [7] and the case study being discussed in this research. The comparison of elicitation process that currently proposed with previous study [7] will also discuss in this Section.

From the case study, we have identified seven goals and eight tasks to achieve the goals, two resources to support tasks and goals, and four actors. We also have defined a total of 12 KPIs for each goal to be achieved and made sure that all goals could be implemented in the enhanced information system. This approach have elicited a set of system requirements that are related to goals, tasks, resources and actors. All these elements have been described in Initial Goal Model Tree.

The Initial Goal Model Tree was extracted specifically from the company visions, missions, and objectives (Organization Goals), and was not from user requirements level. Different with previous research, in this case study, the IT goals were especially extracted from list of goals based on Organization Goals that the current information system can not achieve. The KPIs related to the goals have been identified and we have been able to demonstrate how they become a constraint to the user requirements that caused by the interest or routines procedures of the users. 
With KPIs, some user interest we found in this case could also be eliminated and the system function could be stricter and with maximum control in order to achieve defined goals. For example in this case study, the AR teams calculated the wrong price and tax calculation for their returning purchase goods. The AR teams would ask to open the price if they want to return the goods, not based on the price of invoice they want to return and based on the date of the calculation. They wanted to change the price as they like and claimed that their supplier wanted the calculation procedure as such. The business consultant developer would only need to make sure of the goals of this calculation. If the goal is to make COGS calculation based on standard accounting rules, the price and tax calculation of returning goods must be based on the invoice's price and cannot modified by users. Therefore, the developer no longer have to follow the users' wants, but we can elicit the information system requirements based on goals. If we do not use KPIs to control user requirements, the tasks or resources extracted from goals may arise based on routine procedures of the user or user current knowledge of the system, as in the previous research[9]. Also shown in the example above, user can achieve control purchase returns goal of the task of calculating COGS with the price decided by AR teams, but in this case study, we put "Accurate COGS and Tax Calculation based on invoice and Good Receipt Note (GRN)" as the KPI to control and make sure that the user cannot change the price based on nothing.

In this distribution company, the organization goals were not only extracted to IT goals, but also extracted to unfinished or unsolved goals in their existing information system. In this case study, it has been show that was easier to determine the goals in the company which has an existing information system, because the company has assigning which parts or goals that needed by information system enhancement. The indentifying goal activity in current case study was faster than previous research.

In this case study, elicitation process took little time to finish because everyone has had experience in the existing information system. The stakeholders just collected and made a list of problems in their existing information system, and then we started the discussion based on that. In a company with no information system, initial meetings may need to be conducted for at least four times, the first meeting was to identify and extract organization goals into IT goals, the second to identify business domains and KPIs, the third to identify constraints and to discuss about the organization's beliefs or expectations, and the final one to discuss technical issues. In a company with a preexisting information system, only at least 2 meetings are necessary, the first to identify all current problems and KPIs, and the second for technical issues discussion. With this approach, the business consultant developer and system analyst developer should have enough expertise and experience in same business domain as the company, thus they should be able to help the stakeholders to decide the KPIs.

The result and contribution of this approach based on implementation of organization goal-oriented requirements elicitation (OGORE) process in this case study, as follow:

1. OGORE can indetify and define general goals;

2. OGORE can identify and define specific main goals based on organization goal, that determine by highlevel stakeholder;

3. OGORE can define and specify these goal tree model element as system requirements:
a. Goals
b. Task
c. Resource
d. Actor
e. KPIs

4. OGORE has done these all activities as elicitation process:
a. Elicit high-level stakeholder needs
b. Identify business domain
c. Elicit functional requirements
d. Identify KPIs

5. OGORE can be modeled in the form of Initial Goal Tree Model;

6. OGORE can be documented in the form of Software Requirements Spesification.

\section{CONCLUSION}

In this paper, we have introduced how enhancement of information system requirements can be elicited from organization goals and IT Goals. We also showed in this paper how to define and integrate KPIs into each goal to make sure that each goal can be achieved using the enhanced systems requirements. Different from an organization with no preexisting information system, in this case study, the KPIs can be more easily identified because based on the current information system, the stakeholders can make a list of problems that still arise in the current times. The requirements elicitation process also became simplyfy 
because all high level stakeholder can learn from current problems and experience using the information system.

From this research, we believe that if KPIs defined can be more reliable and conform exactly to goals and the company's business domains, the new information system will have better quality and will not interfere with users' interest. To further verify and analyze this, we need to conduct a variety of case studies using this approach, and propose requirements refinement and analysis based on this elicitation process.

For future works, a different case study from a different domain can be performed to improve the proposal. To enhance the proposal, goals and KPIs may come from reference-based by Cased Based Reasoning [19] Information System usage experience. The case based reasoning system provides proven solution in information system function so that it can be used as references in the requirements analysis and refinement process. There also needs to be an analysis of measurement to make sure that goals and KPIs are of good quality and are highly related to the relevant information system requirements.

\section{REFERENCES}

[1] G. D. Bhatt and V. Grover, "Types of Information Technology Capabilities and Their Role in Competitive Advantage: An Empirical Study," J. Manag. Inf. Syst., vol/issue: 22(2), pp. 253-277, 2005.

[2] B. Ives and G. P. Learmonth, "The information system as a competitive weapon," Communications of the ACM, vol/issue: 27(12). pp. 1193-1201, 1984.

[3] S. Besrour and I. Ghani, "Measuring Security in Requirements Engineering," Int. J. Informatics Commun. Technol., vol/issue: 1(2), pp. 72-81, 2012.

[4] A. Subiyakto, et al., "Influences of the Input Factors towards Success of An Information System Project," TELKOMNIKA (Telecommunication Comput. Electron. Control., vol/issue: 13(2), pp. 686, 2015.

[5] F. Adikara, et al., "The Emergence of User Requirements Risk in Information System Development for Industry Needs," in 6th International Seminar on Industrial Engineering and Management, 2013.

[6] F. Adikara, et al., "Goal-Oriented Requirements Engineering: State of the Art And Beyond," in The 2nd International Confrence on Information Technology and Business Application, 2013.

[7] F. Adikara, et al., "A New Proposal for The Integration of Key Performance Indicators to Requirements Elicitation Process Originating from Organization Goals," in International Conference on Data and Software Engineering, 2014.

[8] K. C. Laudon and J. P. Laudon, "MANAGEMENT INFORMATION SYSTEMS : Managing the Digital Firm," 14th ed. Prentice Hall, 2015.

[9] F. Adikara, et al., "Penerapan Goal Oriented Requirements Engineering ( GORE ) Model ( Studi Kasus: Pengembangan Sistem Informasi Penjaminan Mutu Dosen ( SIPMD ) pada Institusi Pendidikan Tinggi )," in Seminar Nasional Sistem Informasi Indonesia, pp. 230-235, 2013.

[10] S. Faily, "Bridging User-Centered Design and Requirements Engineering with GRL and Persona Cases," Proc. 5th Int. $i^{*}$ Work., 2011

[11] A. Ullah and R. Lai, "MODELING BUSINESS GOAL FOR BUSINESS / IT ALIGNMENT USING REQUIREMENTS ENGINEERING,” J. Comput. Inf. Syst., pp. 21-28, 2011.

[12] ITGI, "COBIT 5 Framework," 2012.

[13] G. Regev and A. Wegmann, "Where do goals come from: the underlying principles of goal-oriented requirements engineering," IEEE, pp. 353-362, 2005

[14] D. Amyot, et al., "Evaluating goal models within the goal-oriented requirement language," Int. J. Intell. Syst., vol/issue: 25(8), pp. 841-877, 2010.

[15] D. Parmenter, "Key Performance Indicators (KPI): Developing, Implementing, and Using Winning KPIs, 2nd ed," New Jersey, Wiley, 2010.

[16] Public Record Office Victoria, "Guidelines 3: Key Performance Indicators," 2010.

[17] K. Tutorial, “A KAOS Tutorial,” Int. J. Infect. Dis. IJID Off. Publ. Int. Soc. Infect. Dis., vol/issue: 12(5), pp. 1-46, 2007.

[18] E. S. K. Yu, "Towards Modeling and Reasoning Support for Early-Phase Requirements Engineering," in RE 97 Proceedings of the 3rd IEEE International Symposium on Requirements Engineering, pp. 226-235, 1997.

[19] A. Aamodt, "Case-Based Reasoning : Foundational Issues , Methodological Variations , and System Approaches," AI Commun., vol. 7, pp. 39-59, 1994. 